\title{
Intergenerational Bubbles of Beliefs for Sustainability
}

\author{
Keiichiro Kobayashi ${ }^{1,2,3,4, *}$ and Asako Chiba ${ }^{1}$ \\ 1 Tokyo Foundation for Policy Research, Tokyo 1066234, Japan; asakochiba01@gmail.com \\ Faculty of Economics, Keio University, Tokyo 1088345, Japan \\ The Canon Institute for Global Studies, Tokyo 1006511, Japan \\ 4 Research Institute of Economy, Trade and Industry, Tokyo 1000013, Japan \\ * Correspondence: keiichirokbys@gmail.com
}

Received: 16 October 2020; Accepted: 15 December 2020; Published: 20 December 2020

check for updates

\begin{abstract}
We constructed a simple model of a dynamic economy in which the current generation chooses to excessively consume, thereby rendering society unsustainable. In such an economy, we assumed that a notional bubbly asset emerges, and its value grows if the current generation conserves adequate resources for future generations. Provided that the bubbly asset is considered valuable, the current generation chooses to conserve resources, rendering the economy sustainable. The condition for sustainability is that the value of this asset grows intergenerationally and indefinitely. The asset represents a belief system, such as a religious doctrine or a political ideology. Results imply that, to restore sustainability, a new intergenerational belief system must be identified, and its value grows indefinitely.
\end{abstract}

Keywords: belief system; intergenerational altruism; rational-expectations equilibrium; unlimited growth

\section{Introduction}

All humans are mortal. Naturally, human beliefs include certain aspects that are intrinsically unverifiable, such as the uncertainty of what happens after we die. Nevertheless, these beliefs drive the decisions and actions of individuals to a certain extent, which determines the sustainability of society. Some beliefs or norms give human beings a desire to outlive themselves after their death, which could be expressed as "generativity" [1]. However, certain practices in the modern world might make people unable to consider future generations, rendering contemporary society unsustainable.

As we review in the next section, prior studies widely acknowledge that human beings and contemporary society often forget about future generations. Under the existence of the market economy and democratic decision making, the decision maker today is the current generation, which tends to be myopic and optimistic [2]. Many economic analyses on sustainability do not intensely incorporate beliefs; they depict that utility-maximizing agents act for their own sake, leaving little or nothing for their descendants, and suggest that policy interventions are necessary to enable sustainable growth. The open question that we address in this paper is, thus, whether sustainability can be restored by endogenous changes in human belief systems rather than by policy intervention or government regulations.

In contrast to the traditional economic literature on sustainability, in which selfish and rational agents lack the motivation to save resources for the future, this paper discusses how even rational people willingly save resources for the next generation by introducing some social device or a belief system. It also illustrates the nature of human beliefs that drives our choice of actions/decisions that change the quality of life from generation to generation. We formulate a simple theoretical economic model that describes how rational utility-maximizing agents could make society sustainable. In general, rational agents in each generation have the incentive to exhaust the benefit of natural resources that they inherited from their ascendants. This society is intrinsically unsustainable because the next generation 
cannot enjoy the same benefits that they could otherwise. If a social device is introduced, agents in each generation maintain the resources at their own expense, such that subsequent generations can reap the benefits. When agents in the next generation pass the resources on, they maintain the resources at their own expense. With the repetition of this altruistic investment, natural resources are never exhausted. Such a society can be called sustainable.

What is the necessary social device to achieve sustainability? Clearly, it is a common belief shared by every agent in every generation that there exists a notional asset of which the value grows forever if all generations maintain natural resources. Suppose that there exists a notional asset, and that all people in the current generation believe that the value of the asset is immensely high and grows if they save an adequate amount of natural resources for future generations. Although saving resources reduces the current generation's consumption, rational people in the current generation save resources voluntarily because doing so increases the value of the notional asset, which compensates for the decrease in consumption. In this way, the notional asset can encourage each generation to maintain natural resources, rendering society sustainable. This study suggests that sustainability is achieved if the belief that the asset has a growing value is commonly shared. The asset is characterized as a "bubbly asset" inherited through generations. A bubbly asset is an asset that has a higher price than what can be justified by the flow of dividends.

Although the term "bubble" often refers to an asset price, a bubbly asset here is the model of a religious doctrine or a political ideology. A doctrine or an ideology can be viewed as an asset or something valuable for the holder because it may improve the quality of life of not only the believers but also of their descendants, mainly in terms of spiritual aspects. Formally, a bubble is defined as a sharp rise in asset price with the expectation of its further rise rather than its use or earning capacity [3]. A doctrine or ideology is bubbly in the sense that its value is not supported by any measurable benefit. In other words, religions or ideologies do not provide material dividends to the believers. Thus, the theory reinterprets not only the concept of sustainability in an economic context but also the potential mechanism of religion or ideology that strengthens sustainability. The model also clarifies the necessary conditions for a new (potential) social device that restores sustainability in the modern world.

We summarize the findings as follows. Methodologically, we describe a generational economy as a dynamic-programming problem in which it is not necessary to impose the transversality condition (TVC), in contrast to the usual dynamic programming in economics. The key feature of bubbly assets, such as a religious belief system or a political ideology, to make human societies sustainable is unlimited growth in the value of the assets. Human beings have a natural tendency to discount the future; hence, the present value of an asset in the future should be lower. If there is no growth in value, this leads to a unique inference that the value of the bubbly asset is always zero, assuming that it does not generate dividends in a finite period. Therefore, the value of the bubbly asset should grow forever if it has a positive value at all. This condition for sustainability is satisfied if there exists a common belief that the value of the notional asset, such as a religious doctrine or a political ideology, grows over time if the current generation maintains an adequate amount of resources for future generations. Our analysis implies that the above-mentioned common belief makes people voluntarily maintain resources, rendering society sustainable in a certain environment. That is, we may need a value system that expands intergenerationally to make our society sustainable.

The notion of bubbles or bubbly assets is popular in economics. An asset enters a bubble or is called a bubbly asset when it trades at a positive value in the market even though it does not generate any dividends and has no intrinsic worth. A well-known example of a bubbly asset is money. Paper money issued by a central bank neither generates any dividend nor has any practical use. In this study, we consider a "pure" bubble, which does not provide any value, whether by means of payment or liquidity. This bubble is valuable today because people believe it will be valuable 
tomorrow. The rationale for this reasoning is as follows. Generally, the value of an asset in period $t, b_{t}$, is calculated as the sum of the dividend, $d_{t}$, and the present value of the asset in period $t+1, b_{t+1}$ :

$$
b_{t}=d_{t}+\beta b_{t+1}
$$

where $\beta(<1)$ is the discount factor, which is usually $\frac{1}{1+r}$, and $r$ is the market rate of interest. When the asset is in a bubble that generates no dividends $\left(d_{t}=0\right)$, then the value satisfies $b_{t+1}=\beta^{-1} b_{t}$. This law of motion implies that the value of the asset, $b_{t}$, must grow over time at the rate of $\beta^{-1}(>1)$. According to standard economic theories, an unbounded bubble is irrational because this valuation violates the TVC. (The TVC is a condition for rationality in which a rational agent chooses actions such that the present value of the asset in the infinite future converges to zero. In other words, nothing is left unused in the infinite future. The TVC implies that $\lim _{t \rightarrow \infty} \beta^{t} b_{t}=0$. This condition is obviously violated if $b_{t}=\beta^{-t} b_{0}$ and $b_{0}>0$ ). What we consider in this study is not an economic asset subject to the TVC, but a notional asset interpreted as a religious doctrine or political ideology. Thus, unbounded growth is allowed in value $b_{t}$ for an imaginary bubble. In other words, we can assume that the current generation considers the asset valuable purely because they believe that the next generation will perceive it as valuable. Considering the mortality of humans and the uncertainty that follows, this expectation of the value of a notional bubble, such as a religious doctrine or political ideology, cannot be dismissed as irrational.

The remainder of this paper is structured as follows. The two following sections briefly explain the related literature and the used method to solve the problem. Section 4 presents a model of an intrinsically unsustainable human society. Section 5 demonstrates that an intergenerationally inherited bubbly asset can make society sustainable, and clarifies the conditions for sustainability. Section 6 concludes the paper.

\section{Literature Review}

In the economics literature, the authors in [4-6] were pioneers in the discussion of economic growth and sustainability (see [7] for a review). In [4], the authors showed that laissez-faire equilibrium leads to the depletion of limited resources and diminishing consumption under a positive discount rate. The authors in [5] indicated that sufficiently fast technological progress is necessary to maintain growth, while [6,8] focused on the substitution between capital and natural resources as production inputs. In [8], the authors claimed that, under the condition that natural resources are limited, the production function must allow for infinite substitution between capital and natural resources to achieve constant consumption that enables sustainable growth. However, growth under infinite substitution between inputs is unrealistic; a sufficiently large amount of capital that compensates for the scarcity of natural resources requires mandatory capital accumulation. In addition, the speed of capital accumulation should be sufficiently high to offset its downward pressure on the interest rate. The authors in [9], pointing out limited substitutability, suggested principles to maintain sustainability, such as harvest rates not exceeding regeneration rates, and waste rates not exceeding natural purification rates. Although these principles are strong, and some authors raise criticisms about their feasibility (see, e.g., [10]), the notion that policies that force people to act considerately can achieve sustainability is widely shared in reality. In this context, the present paper provides another view of sustainability: under common beliefs, utility-maximizing people willingly decrease their own consumption for future generations. Technically, the problem of sustainability that we consider in this paper is the same as the setting of the intergenerational sustainability dilemma game presented in [11].

Future design describes such voluntary sacrifice as a result of the activated human trait of futurability, namely, in the words of [12], "where people experience an increase in happiness because of deciding and acting to forego current benefits in order to enrich future generations". In terms of economic theory, the introduction of imaginary future generations in future design corresponds to the increase in the value of the discount factor, that is, the weight that the current generation assigns 
to future generations' utility [13]. Reconstructing social systems that force people to consider future generations increases the discount factor, and people make sustainable decisions. To analyze the effectiveness of such reconstruction, some studies conducted experiments by introducing imaginary future generations in voting systems or deliberation [14,15]. However, as in the review by [2], neither voting systems nor deliberation could arouse people's consideration for future generations.

The authors in $[16,17]$ indicate that those who recognize themselves as logical and curious can act as an imaginary future generation. In reality, such people do not constitute the majority of the population. Thus, it is difficult to lead people to place a high value on the utility gain of future generations. Complementarily, common beliefs work as a device to create a sustainable society by guaranteeing future generations' consumption. The difference between our study and those existing in the sustainability literature is that we do not discuss government interventions, including regulations and policies. From a theoretical perspective, our model features the introduction of common beliefs as a bubbly asset. An important aspect of such modeling is that it relates future design to what [2] calls "past design". In [18], the authors show that people come to favor the preservation of natural resources after learning about past events. Hence, the acquisition of intergenerational retrospective viewpoints leads people to placing a high value on what they inherited from their ancestors. The present paper theoretically describes that evaluations of both the future and the past matter by showing that a sufficiently high initial value of an asset is a necessary condition for sustainable growth to arise.

We describe the mechanism by which common beliefs succeed from generation to generation as a "bubble". There is a long debate over the existence of bubbles in general settings in economic theory ([19]). Under the TVC, which ensures that every asset is consumed in the infinitely far future, the price of an asset should be equal to the expected discounted cash flow because the expected terminal value of that asset is zero. Prior studies show that bubbles can emerge under several assumptions. A classic strand of the literature rationalizes the emergence of bubbles by dynamic inefficiency in the overlapping generation models: each generation lives for a finite time; thus, it accumulates capital beyond the socially optimal level in equilibrium. In this environment, bubbles, which provide a means of storing assets besides capital, mitigate dynamic inefficiency ([20-22]). However, their models feature a net decline in investment in the boom episodes, namely, a cloud-out effect, which is counterfactual. Against this, Ref. [23] introduced financial frictions to allow for the coexistence of efficient and inefficient projects in financial markets, and showed that bubbles allocate resources from inefficient to efficient investments. In [24-26], the authors assumed borrowing constraints, while [27] showed that even, if arbitragers were rational, asymmetric information would generate bubbles: the variety of timings in which they notice that the asset price is beyond the fundamental value differentiates their opinions on the time to sell the asset, which makes the bubble persist for finite periods of time and eventually burst. The authors in $[28,29]$ focused on the agency problem in investment: fund managers with fixed-year contracts or under pressure to buy assets are willing to invest in bubbles, ignoring the possibility of incurring losses on investor money. Several other studies incorporated heterogeneous beliefs, as in the review by [30]. While these works deal with bubbles in financial assets, we interpret the term "bubble" in a broader sense: religious doctrines and political ideologies are also bubbly assets, as their value is supported only by the agents' beliefs. As noted in the introduction, these doctrines and ideologies are not consumed like financial assets; thus, the model does not satisfy the TVC, and we allow for infinite growth in the value of the asset.

\section{Methodology}

We adopted the dynamic-programming method to solve the proposed model, although the background of its introduction is different from that in standard macroeconomics. This difference is crucial because of the absence of the TVC in the present model. A simple explanation for dynamic programming in standard macroeconomics is as follows. Agents choose their control variables to maximize the objective function subject to constraints. For instance, a representative agent with an infinite time horizon maximizes their lifetime utility subject to their budget constraint by choosing 
a consumption profile. Their lifetime utility is defined as the discounted sum of utility in the future, with each periodic utility given by an increasing and strictly concave function of consumption during that period. In this model, the agent's control variables are consumption in each period from today, which means that the agent chooses an infinite number of variables. To make this sequential problem feasible, a value function is introduced. A value function at a certain period is defined as the maximized lifetime utility from then on. By replacing utility in the future with the value function, the problem is rewritten in recursive form, called the Bellman equation. The agent then only chooses today's consumption. Formally, solving the original sequential problem is equivalent to solving the Bellman equation, in the sense that there exists a unique solution to the Bellman equation that is also a unique solution to the sequential problem. The equivalence between these two problems holds in general settings, including the TVC, which means that asset holders lastly spend all their wealth on consumption (see [31-33]).

Meanwhile, the present model assumes that agents live only for one period and the next generation inherits their assets. In addition, agents are altruistic in the sense that they account for their descendants' utility. These settings create two parts to the rational agents' utility: their own utility today and the expected utility their descendants will gain in the future. Thus, the agent's utility maximization problem is not a sequential problem but takes the form of the Bellman equation as in the original problem. Thus, unlike in standard macroeconomic models with infinitely lived agents, the Bellman equation in our model does not need to be accompanied by the TVC. This is the rationale behind the application of the Bellman equation in our paper.

In general, methods to derive the solution for the Bellman equation are the guess-and-verify method and function iteration. In the former, one first guesses a functional form of the value function and verifies that the function satisfies the Bellman equation. If the Bellman equation is too complicated to guess its solution, then a function iteration is chosen and the value function or policy function is computed for a finite number of states. In the present model, we applied the guess-and-verify method.

\section{Model of an Unsustainable Society without Bubbly Assets}

This section presents the model in the infinite horizon. We first outline the concept in a simplified two-period version. Suppose that people have an endowment today that they should allocate between consumption and investment to maintain an asset. If they invest today, then the value of the asset tomorrow would be higher than the value is today; if they do not invest, the value of the asset becomes zero. In such an environment, how much do they consume and invest today, given that people maximize their welfare, which consists of their utility from consumption today and discounted value of the asset tomorrow? Assuming that the value of the asset is growing and is sufficiently high today, they would choose to invest a certain amount by giving up their consumption. This is because investing in the asset today brings more welfare than consumption today does, as the expected value of the asset tomorrow is higher and compensates for the lower consumption today. This simple model illustrates that utility-maximizing people could act in consideration for the future. The mechanism here is that society has an asset of which the value is growing, given that each generation makes the investment. To clarify this point, we describe the formal model below.

Consider a closed economy model where time is discrete: $t=0,1,2, \ldots, \infty$. At the beginning of each period $t$, one representative agent of Generation $t$ is born and dies by the end of the same period, while their child, the representative agent of Generation $t+1$, is born in period $t+1$. The representative agent of Generation $t$ is altruistic in the sense that their belief in their child's welfare enters their own welfare, as we show below.

The model is simple and focuses on the key drivers of sustainability. We can assume that Generation $t$ chooses only one control variable, $c_{t}$, lifetime consumption, to maximize lifetime welfare $V_{t}$ while receiving an endowment of consumption goods, $y_{t}$. We define lifetime welfare as $V_{t} \equiv U\left(c_{t}\right)+\beta V_{t+1}^{e}$, where $U\left(c_{t}\right)$ is the utility from consumption $c_{t}$; note that $U(0)=0, U^{\prime}(c) \geq 0$, and $U^{\prime \prime}(c) \leq 0$. Parameter $\beta$, which satisfies $0<\beta<1$, is the discount factor or the degree of 
intergenerational altruism, which indicates how much agent $t$ cares about the welfare of the next generation. Lastly, $V_{t+1}^{e}$ is Generation $t^{\prime}$ s expectation of the lifetime welfare of Generation $t+1$. Thus, Generation $t$ solves the following equation:

$$
\begin{aligned}
& V_{t}= \max _{c_{t}} U\left(c_{t}\right)+\beta V_{t+1}^{e}, \\
& \text { s.t. } \quad c_{t} \leq y_{t},
\end{aligned}
$$

where the value of $V_{t}$ is to be solved, $V_{t+1}^{e}$ is given, and $U\left(c_{t}\right)$ is given by nature and is a known function. Endowment $y_{t}$ is also taken as given by agent $t$. The solution to this maximization problem is merely

$$
c_{t}=y_{t}
$$

and the value of lifetime welfare is $V_{t}=U\left(y_{t}\right)+\beta V_{t+1}^{e}$.

We can describe the sustainability problem in this model simply as follows. In initial period $t=0$, the endowment is $y>1$; that is, $y_{0}=y$. For $t \geq 0$, Generation $t$ faces the following intergenerational trade-off: if $y_{t}=0$ or $y_{t}=y$ and the agent consumes more than $y-1$ (i.e., $c_{t}>y-1$ ), then the endowment for the next generation becomes 0 (i.e., $y_{t+1}=0$ ), whereas if $y_{t}=y$ and the agent consumes no more than $y-1$, that is, $c_{t} \leq y-1$, then $y_{t+1}=y$.

This simple trade-off represents the environmental trade-off in the real world. If the current generation excessively consumes natural resources, then there is inadequate renewal of resources, and our descendants would not enjoy similar living standards.

Under the intergenerational trade-off, the equilibrium path of the economy that is a solution to Optimization Problem (1) for Generation $t$ is

$$
c_{t}= \begin{cases}y, & \text { for } t=0 \\ 0, & \text { for } t \geq 1\end{cases}
$$

In the equilibrium, the economy is unsustainable because the current generation (Generation 0) consumes everything, and future generations (Generations $t(\geq 1)$ ) consume nothing. The value of lifetime welfare is

$$
V_{t}= \begin{cases}U(y), & \text { for } t=0 \\ U(0)=0, & \text { for } t \geq 1\end{cases}
$$

Typical economic models assume that people or generations are rational, and that each generation rationally predicts the lifetime welfare of the next generation. Thus, by the assumption of rationality,

$$
V_{t+1}^{e}=V_{t+1}, \text { for all } t \geq 0 .
$$

Therefore, in equilibrium,

$$
V_{t+1}^{e}=U(0)=0, \text { for all } t \geq 0 .
$$

Consequently, each generation maximizes only its own welfare despite knowing that the next generations suffer from a shortage of resources. Because $V_{t+1}^{e}=0$ is considered as a given, each generation fails to understand that its actions can change the welfare of the next generation.

A note on collective decision making: The aforementioned argument is based on the (implicit) assumption that each generation consists of an infinite number of individuals who are unable make a collective decision. Collective decision making means that all agents in Generation $t$ collectively decide the same consumption level $c_{t}$. If collective decision making is possible, then Generation $t$ 
could choose $c_{t}=y-1$ to make society sustainable. However, we assumed that $\beta$ is sufficiently low to satisfy the following inequality:

$$
U(y)>\frac{1}{1-\beta} U(y-1)=\sum_{t=0}^{\infty} \beta^{t} U(y-1) .
$$

The left-hand side of the inequality is welfare $V_{0}$ in the path in which Generation 0 chooses $c_{0}=y$, and subsequent Generations $t$ are forced to choose $c_{t}=0$ for $t \geq 1$. The right-hand side is welfare $V_{0}$ in the path in which all generations choose $c_{t}=y-1$, given that the agents are rational (i.e., $V_{t+1}^{e}=V_{t+1}$ ) because $V_{t}=U(y-1)+\beta V_{t+1}$, implying that $V_{0}=U(y-1)+\beta V_{1}=U(y-1)+\beta U(y-1)+\beta^{2} V_{2}=$ $\cdots=\sum_{t=0}^{\infty} \beta^{t} U(y-1)$ in the path where $c_{t}=y-1$ for all $t$. Thus, Condition (3) implies that $\beta$ is sufficiently low so that the lifetime welfare of the current generation (Generation 0 ) is higher when they choose $c_{0}=y$ than when they choose $c_{0}=y-1$, and subsequent generations also choose $c_{t}=y-1$ for all $t \geq 1$. Therefore, under Condition (3), Generation 0 chooses $c_{0}=y$ even if they can make the decision collectively. In other words, generations choose $c_{t}=y-1$, and society becomes sustainable if $\beta$ is sufficiently high and close to one, such that Condition (3) is violated in an economy in which they make collective decisions.

\section{Model of a Sustainable Society with Bubbly Assets}

In the previous section, we demonstrated that the economy is not sustainable when the current generation maximizes its own welfare even though they are altruistic towards their descendants to a certain degree. In this section, we illustrate the restoration of sustainability. We assumed the existence of an intergenerational bubbly asset, such as religious doctrine or a political ideology, and the value of the asset indefinitely grows over time.

We assumed that people in this economy begin to believe that an imaginary asset exists, of which the value is $b_{t}$. Each Generation $t$ can invest $x_{t}$ units of consumption goods in the asset, which determines the value of asset $b_{t+1}$ for the next generation. For simplicity, we assumed that Generation $t$ could choose either $x_{t}=1$ or $x_{t}=0$. We assumed that people also believe that the law of motion of $b_{t}$ is given by $b_{t+1}=F\left(b_{t}, x_{t}\right)$, where

$$
F\left(b_{t}, x_{t}\right)= \begin{cases}\beta^{-1} b_{t}, & \text { if } x_{t}=1 \\ 0, & \text { if } x_{t}=0 .\end{cases}
$$

Variable $b_{t}$ is a state variable that is predetermined in period $t$, before the agent chooses action $c_{t}$. Thus, we can describe the value of welfare $V_{t}$ as a function of $b_{t}$; that is, $V_{t}=V\left(b_{t}\right)$. Given these beliefs $\left\{b_{t}, F\left(b_{t} \cdot x_{t}\right)\right\}$, Generation $t$ solves

$$
\begin{gathered}
V\left(b_{t}\right)=\max _{x_{t} \in\{0,1\}} U\left(c_{t}\right)+\beta V^{e}\left(b_{t+1}\right), \\
\text { s. t. } \quad c_{t}+x_{t}=y_{t} \\
\\
b_{t+1}=F\left(b_{t}, x_{t}\right),
\end{gathered}
$$

where function $V(b)$ is unknown and can be derived by solving the aforementioned problem. Generation $t$ takes $V^{e}\left(b_{t+1}\right)$ as given, where $V^{e}\left(b_{t+1}\right)$ is Generation $t^{\prime}$ s expectation of the lifetime welfare of Generation $t+1$. Rationality Condition (2) or

$$
V^{e}(b)=V(b)
$$

must be satisfied in equilibrium. If the initial value of $b_{t}$ is zero $\left(b_{0}=0\right)$, then Problem (4) reduces to Problem (1), and the equilibrium is reduced to the unsustainable path, that is, $c_{0}=y$ and $c_{t}=0$ for $t \geq 1$. 
For a larger initial value of $b_{0}$, we can identify another solution to Problem (4) that satisfies rationality $\left(V(b)=V^{e}(b)\right)$ using the guess-and-verify method. First, we guessed that the value function that satisfies (4) is $V(b)=\hat{V}+\phi b$, where $\hat{V}=\frac{1}{1-\beta} U(y-1)$ and $\phi>0$. Thus, we assumed that $V^{e}\left(b_{t+1}\right)=\hat{V}+\phi b_{t+1}$. If Generation $t$ chooses $x_{t}=0$, then $c_{t}=y$ and $b_{t+1}=0$. In this case, $V\left(b_{t}\right)=U(y)+\beta \hat{V}$. If Generation $t$ chooses $x_{t}=1$, then $c_{t}=y-1$ and $b_{t+1}=\beta^{-1} b_{t}$. In this case, $V\left(b_{t}\right)=U(y-1)+\beta\left[\hat{V}+\phi \beta^{-1} b_{t}\right]=\hat{V}+\phi b_{t}=V^{e}\left(b_{t}\right)$. We focused on the case where the initial $b_{0}$ is sufficiently large, such that

$$
U(y)+\beta \hat{V}<\hat{V}+\phi b_{0} .
$$

This inequality does not hold for $b_{0}=0$, as $U+\beta \hat{V}<\hat{V}$ contradicts Assumption (3). With a sufficiently large $b_{0}$, Generation $t$, which maximizes its own welfare given the belief that $V^{e}(b)=$ $\hat{V}+\phi b$, chooses $x_{t}=1$ for all $t \geq 0$. This generation's choice $x_{t}=1$ justifies its belief $\left(V^{e}(b)=\hat{V}+\phi b\right)$ as a rational expectation, that is, $V^{e}(b)=V(b)$. We thereby justify the guess that the value function is $V(b)=\hat{V}+\phi b$. In this equilibrium, $y_{t}=y$ and $c_{t}=y-1$ for all $t$, which means that the economy is sustainable. (The rational bubble that solves Problem (4) is not unique. Our solution, $b_{t+1}=\beta^{-1} b_{t}$, is one deterministic example of infinitely many stochastic bubbles that solve Problem (4) and satisfy $E_{t} b_{t+1}=\beta^{-1} b_{t}$, where $E_{t}$ is the expectation operator. Even in the case of a stochastic bubble, society is sustainable as long as bubble $b_{t}$ continues to grow).

In a sustainable equilibrium, Generation $t^{\prime}$ s belief that its descendants' welfare is $V^{e}\left(b_{t+1}\right)=$ $\hat{V}+\phi b_{t+1}$ implies that its own welfare is $V\left(b_{t}\right)=\hat{V}+\phi b_{t}$. In other words, if an agent believes that their descendant would obtain direct utility from the asset, $\phi b_{t+1}$, then the agent obtains direct utility from the asset, $\phi b_{t}$. (Although our theory focuses on a belief system being described as a bubbly asset that can restore the sustainability of society, there are other ways to restore sustainability. For example, education, religion, and ideology may contribute to raising discount factor $\beta$, so that Condition (3) is violated, and society becomes sustainable. We can interpret that one aim of the future-design project is to raise $\beta$ by employing a specific method of discussion and/or deliberation. We thank the anonymous referee who indicated this).

\section{Conclusions}

The sustainability of a society is restored when people conserve resources $x_{t}=1$ as an investment in an asset. Individuals are willing to invest because they believe that the asset is more valuable than their current consumption is. Thus, a sustainable path can be realized if people believe that the initial value of the asset $b_{0}$ is sufficiently large, and that $b_{t}$ can be increased by investing $x_{t}=1$. The asset is valuable for the current generation because they believe that their descendants receive direct utility from it. They believe that Generation $t+1$ would receive direct utility of $\phi b_{t+1}$ from holding the asset and that $b_{t}$ evolves by $b_{t+1}=\beta^{-1} b_{t}$. Given this belief, Generation $t$ receives direct utility of $\phi b_{t}$ from holding the asset.

A sustainable path is the rational expectations equilibrium because condition of rationality $\left(V(b)=V^{e}(b)\right)$ is satisfied. Law of motion $b_{t+1}=\beta^{-1} b_{t}$ ensures that rationality is satisfied. Recall that $V\left(b_{t}\right)$ is given by $V\left(b_{t}\right)=U(y-1)+\beta\left[\hat{V}+\phi b_{t+1}\right]$ on the premise that $V^{e}(b)=\hat{V}+\phi b$. Rationality $\left(V(b)=V^{e}(b)\right)$ implies that $V\left(b_{t}\right)=\hat{V}+\phi b_{t}$. As $U(y-1)+\beta \hat{V}=\hat{V}$, rationality is satisfied if $b_{t+1}=\beta^{-1} b_{t}$. Therefore, we can state that if people have a belief that $b_{t+1}=\beta^{-1} b_{t}$, there exists a sustainable rational-expectations equilibrium.

The asset in this model represents a belief system, such as a religious doctrine or a political ideology. One puzzling fact that requires an explanation in social science is that a successful and prevailing religion or ideology in the modern world exhibits noticeable expansibility. Our theory demonstrates that a religion or an ideology can make a human society sustainable if the value of the doctrine or ideology indefinitely grows. This relationship between the sustainability of a society and the growth of the value may account for the expansibility of successful religions or political ideologies. 
This result is insightful because it indicates that we need a new belief system with indefinitely growing value to restore the sustainability of modern society in which altruism towards one's descendants is insufficient. Developing or identifying a future-oriented value system should be a primary goal in future-design research.

Lastly, this paper is a first step, and much more research is needed to clarify the nature of the relationship between intergenerational belief systems and the sustainability of our society. Our model is too simplistic to make any quantitative predictions, but it can qualitatively demonstrate the effect of an expansionary belief system on sustainability. Many questions concerning the quantitative predictions of the model remain to be answered. To test the applicability of our framework, it may be useful to investigate historical data and observe how the longevity of human societies is linked to the nature of their religions. All these agendas are left for future research.

Author Contributions: K.K. constructed the theoretical model of intergenerational bubble; A.C. provided literature review and related the model to the context of future design. All authors have read and agreed to the published version of the manuscript.

Funding: This research received no external funding.

Acknowledgments: We thank Hiroshi Fujiki, Sander van der Leeuw, Tatsuyoshi Saijo, Makoto Yano, and anonymous referees for valuable discussions and encouragements. We also thank seminar participants at the Research Institute of Economy, Trade and Industry, and of the ASU/Future Design/FEAST Workshop on Intergenerational Futures "Opening and Enacting New Futures" at the Research Institute for Humanity and Nature in 2019 for insightful comments.

Conflicts of Interest: The authors declare no conflict of interest.

\section{References}

1. Kotre, J.N. Outliving the Self: How We Live on in Future Generations; Norton \& Co.: New York, NY, USA, 1996.

2. Saijo, T. Future design: Bequeathing sustainable natural environments and sustainable societies to future generations. Sustainability 2020, 12, 6467. [CrossRef]

3. Kindleberger, C.P.; Aliber, R.Z. Manias, Panics and Crashes: A History of Financial Crises; Palgrave Macmillan: London, UK, 2011.

4. Dasgupta, P.; Heal, G. The optimal depletion of exhaustible resources. Rev. Econ. Stud. 1974, 41, 3-28. [CrossRef]

5. Stiglitz, J. Growth with exhaustible natural resources: Efficient and optimal growth paths. Rev. Econ. Stud. 1974, 41, 123-137. [CrossRef]

6. Solow, R.M. Intergenerational equity and exhaustible resources. Rev. Econ. Stud. 1974, 41, 29-45. [CrossRef]

7. Pezzey, J.C.V.; Toman, M. The Economics of Sustainability: A Review of Journal Articles; Discussion Paper 02-03; Resources for the Future: Washington, DC, USA, 2002.

8. Hartwick, J.M. Intergenerational equity and the investing of rents from exhaustible resources. Am. Econ. Rev. 1977, 67, 972-974.

9. Daly, H.E. Toward some operational principles of sustainable development. Ecol. Econ. 1990, 2, 1-6. [CrossRef]

10. Beckerman, W. "Sustainable Development": Is it a Useful Concept? Environ. Values 1994, 3, $191-209$. [CrossRef]

11. Shahrier, S.; Kotani, K.; Saijo, T. Intergenerational sustainability dilemma and the degree of capitalism in societies: A field experiment. Sustain. Sci. 2017, 12, 957-967. [CrossRef]

12. Saijo, T. Future Design. In Future of Economic Design: The Continuing Development of a Field as Envisioned by Its Researchers; Laslier, M., Sanver, Z., Eds.; Springer: Berlin/Heidelberg, Germany, 2019.

13. Saito, M. Does a present generation change its own preferences as a consequence of a discourse with imaginary future generations? Trends Sci. 2018, 23, 16-19. [CrossRef]

14. Katsuki, S.; Hizen, Y. Does voting solve intergenerational sustainability dilemma? Sustainability 2020, $12,6311$. [CrossRef] 
15. Timilsina, R.R.; Kotani, K.; Nakagawa, Y.; Saijo, T. Concerns for Future Generations in Societies: A Deliberative Analysis on Intergenerational Sustainability Dilemma. J. Behav. Exp. Econ. 2021, 90, 101628. [CrossRef]

16. Nakagawa, Y.; Arai, R.; Kotani, K.; Nagano, M.; Saijo, T. Intergenerational retrospective viewpoint promotes financially sustainable attitude. Futures 2019, 114, 102454. [CrossRef]

17. Nakagawa, Y.; Saijo, T. Can Individuals Caring Little about Future Generations Serve as their Representatives? Futures 2020, 124, 102626. [CrossRef]

18. Nakagawa, Y.; Kotani, K.; Matsumoto, M.; Saijo, T. Intergenerational retrospective viewpoints and individual policy preferences for future: A deliberative experiment for forest management. Futures 2019, 105, 40-53. [CrossRef]

19. Stiglitz, J.E. Symposium on bubbles. J. Econ. Perspect. 1990, 4, 13-18. [CrossRef]

20. Samuelson, P.A. An exact consumption-loan model of interest with or without the social contrivance of money. J. Political Econ. 1958, 66, 467-482. [CrossRef]

21. Diamond, P.A. National debt in a neoclassical growth model. Am. Econ. Rev. 1965, 55, 1126-1150.

22. Tirole, J. Asset bubbles and overlapping generations. Econometrica 1985, 53, 1499-1528. [CrossRef]

23. Martin, A.; Ventura, J. Economic growth with bubbles. Am. Econ. Rev. 2012, 102, 3033-3358. [CrossRef]

24. Farhi, E.; Tirole, J. Bubbly liquidity. Rev. Econ. Stud. 2012, 79, 678-706. [CrossRef]

25. Martin, A.; Ventura, J. Managing credit bubbles. J. Eur. Econ. Assoc. 2016, 14, 753-798. [CrossRef]

26. Hirano, T.; Yanagawa, H. Asset bubbles, endogenous growth, and financial frictions. Rev. Econ. Stud. 2017, 84, 406-443. [CrossRef]

27. Abreu, D.; Brunnermeier, M.K. Bubbles, and crashes. Econometrica 2003, 71, 173-204. [CrossRef]

28. Shleifer, A.; Vishny, R.W. The limits of arbitrage. J. Finance 1997, 52, 35-55. [CrossRef]

29. Allen, F.; Gorton, G. Churning bubbles. Rev. Econ. Stud. 1993, 60, 813-836.

30. Brunnermeier, M.K.; Oehmk, M. Bubbles, financial crises, and systemic risk. In Handbook of the Economics of Finance; Elsevier: Amsterdam, The Netherlands, 2013; Volume 2, pp. 1221-1288.

31. Stokey, N.; Lucas, R.E.; Prescott, E. Recursive Methods in Economic Dynamics; Harvard University Press: Cambridge, MA, USA, 1989.

32. Ljungqvist, L.; Sargent, T.J. Recursive Macroeconomic Theory; MIT Press: Cambridge, MA, USA, 2000.

33. Sargent, J.J. Dynamic Macroeconomic Theory; Harvard University Press: Cambridge, MA, USA; London, UK, 1987.

Publisher's Note: MDPI stays neutral with regard to jurisdictional claims in published maps and institutional affiliations.

(c) 2020 by the authors. Licensee MDPI, Basel, Switzerland. This article is an open access article distributed under the terms and conditions of the Creative Commons Attribution (CC BY) license (http:/ / creativecommons.org/licenses/by/4.0/). 